\title{
SURGICAL MANAGEMENT OF CONGENITAL OBSTRUCTION OF THE LEFT MAIN CORONARY ARTERY WITH SUPRAVALVULAR AORTIC STENOSIS
}

Patricia A. Thistlethwaite, $\mathrm{MD}, \mathrm{PhD}^{\mathrm{a}}$

Michael M. Madani, MDa

Jolene M. Kriett, MD

Kirk Milhoan, $\mathrm{MD}, \mathrm{PhD}^{\mathrm{b}}$

Stuart W. Jamieson, MB, FRCS
Objective: Stenosis of the left main coronary artery is a recognized complicating feature of supravalvular aortic stenosis. We have retrospectively identified three anatomic subtypes of left main coronary obstruction in patients with supravalvular aortic stenosis, each necessitating a distinct surgical approach.

Methods: From 1991 to 1998, 9 patients underwent surgical repair of supravalvular aortic stenosis and left main coronary stenosis. Five patients (group 1) had obstruction from near-circumferential thickening of the left main ostium, 2 patients (group 2) had restricted coronary flow due to fusion of an aortic valve leaflet to the supravalvular ridge, and 2 patients (group 3 ) had diffuse narrowing of the left main coronary artery. Group 1 patients were treated with patch aortoplasty encompassing the left main ostium and supravalvular aortic stenosis. Group 2 patients were treated with excision of the fused leaflet from the aortic wall and patch aortoplasty. Group 3 patients were treated with bypass grafting and aortoplasty.

Results: Surgical strategy was determined by coronary angiography and intraoperative assessment of coronary anatomy. There was 1 early death. All surviving patients underwent echocardiography with or without postoperative catheterization. The mean postoperative supravalvular gradient for 7 patients was $8 \mathrm{~mm} \mathrm{Hg}$ (range 2-15 mm Hg). One patient required reoperation for a residual aortic gradient as a result of aortic arch involvement. No evidence of left main coronary artery stenosis was seen in groups 1 and 2; bypass grafts were patent in group 3 patients at a mean follow-up of 54.8 months.

Conclusion: Three subtypes of left main coronary stenosis with supravalvular aortic stenosis are described. Each anatomic type mandates an individual surgical approach. Favorable surgical outcomes are achievable with each category. (J Thorac Cardiovasc Surg 2000;120:1040-6)
S upravalvular aortic stenosis (SVAS) is a rare congenital anomaly defined by variable amounts of left ventricular outflow obstruction distal to the aortic

From the Divisions of Cardiothoracic Surgery a and Pediatric Cardiology, ${ }^{\mathrm{b}}$ University of California, San Diego, Calif.

Received for publication March 29, 2000; revisions requested May 4, 2000; revisions received June 7, 2000; accepted for publication June 12, 2000.

Address for reprints: Patricia A. Thistlethwaite, $\mathrm{MD}, \mathrm{PhD}$, Division of Cardiothoracic Surgery, University of California, San Diego, 200 West Arbor Dr, San Diego, CA 92103-8892 (E-mail: pthistlethwaite@ucsd.edu).

Copyright (C) 2000 by The American Association for Thoracic Surgery

0022-5223/2000 $\$ 12.00+0 \quad \mathbf{1 2 / 1 / 1 1 0 4 9 3}$

doi: $10.1067 / \mathrm{mtc} .2000 .110493$ valve. The narrowing resulting from SVAS is due to two pathologic processes: (1) a thickening of the medial layer of the aorta by collagen deposition and smooth muscle cell hypertrophy and (2) fibrosis and thickening of the intimal layer. ${ }^{1}$ The stenosis may be diffuse or localized and is characterized by its location at the level of and distal to the sinotubular junction. ${ }^{2}$ SVAS may occur as part of Williams syndrome or it may be inherited as an autosomal dominant trait or manifest as a sporadic anomaly. In certain families, SVAS is thought to be due to an inherited mutation of the elastin gene on chromosome $7 .^{3}$

Obstruction of the left main coronary artery (LMCA) is a recognized complicating feature of SVAS and is a cause of sudden death in infants with this abnormality. ${ }^{4}$ 

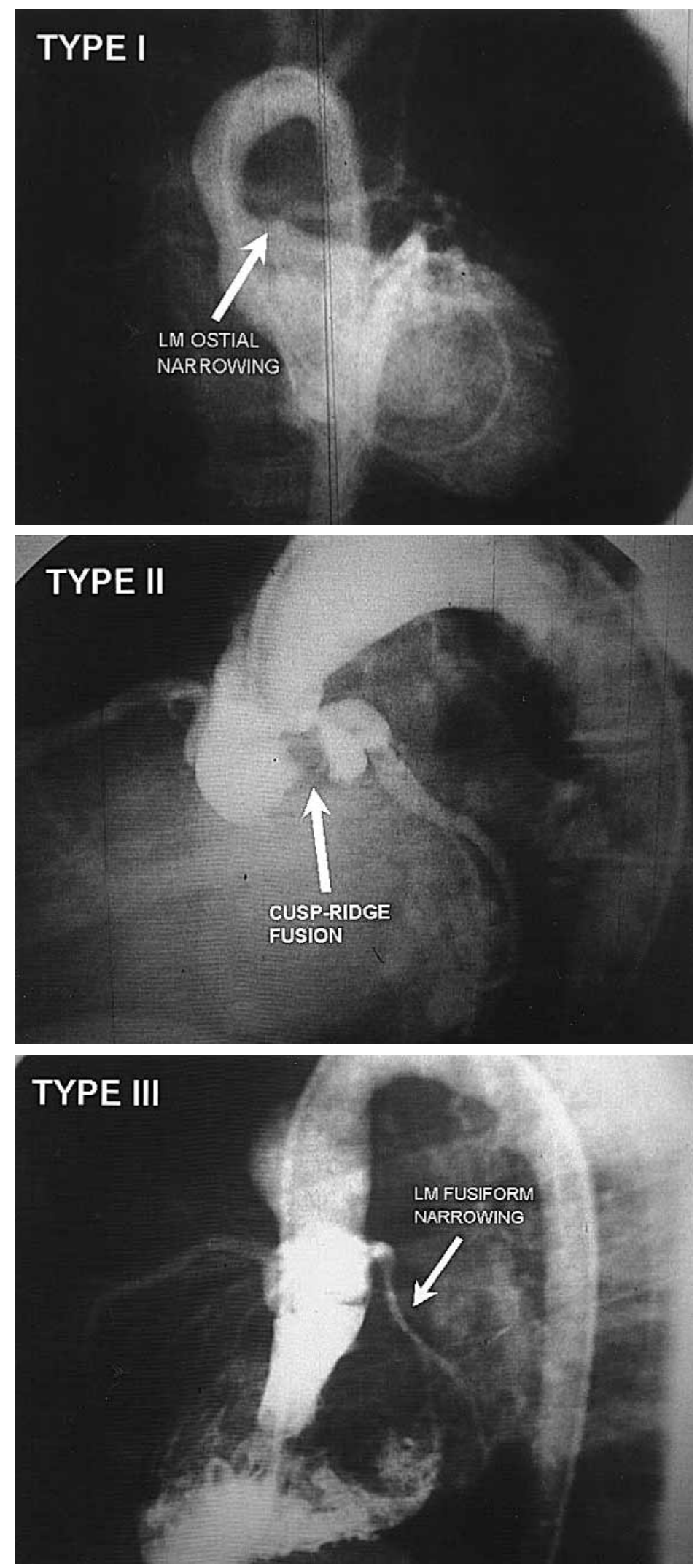

Fig 1. Representative angiograms of three forms of LMCA obstruction with SVAS. $L M$, Left main. 


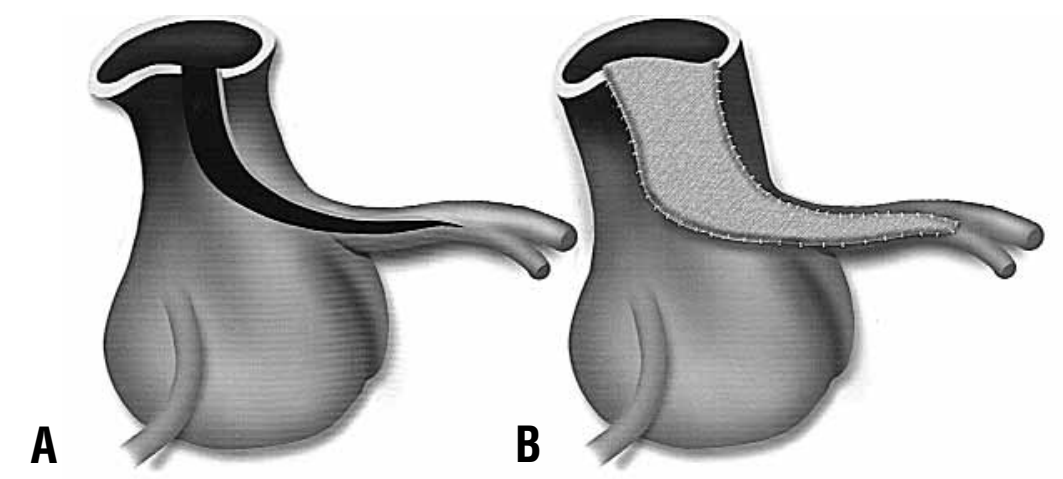

Fig 2. Type I LMCA obstruction. A, The aorta is opened with an oblique aortotomy that extends into the LMCA ostium. B, Enlargement of the ascending aorta and LMCA by patch augmentation.

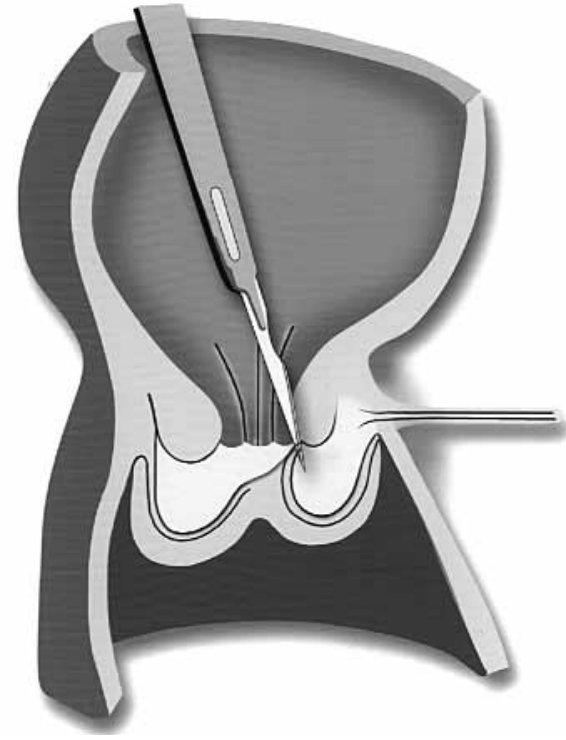

Fig 3. Excision of the left coronary cusp adherent to the supravalvular ridge in type II LMCA obstruction.

Most often, LMCA stenosis is due to a thickening of the wall of the left main ostium that is in tandem with the aortic component of the disease. ${ }^{5}$ Two other mechanisms for LMCA stenosis with SVAS have been identified. In one form, coronary obstruction results from distortion of the aortic valve with adherence of the left coronary leaflet to the proximal ridge of the SVAS. ${ }^{6}$ In the most uncommon form, diffuse LMCA narrowing is noted and may, in part, be due to premature atherosclerosis induced by increased perfusion pressure to the coronary artery in systole. ${ }^{7}$

We report our experience with 9 patients in whom obstruction to LMCA blood flow was a prominent feature associated with SVAS. Three morphologic types of LMCA stenosis were identified, each of which necessitated a distinct surgical approach for anatomic correction.

\section{Patients and methods}

Patient data. From 1991 to 1998,16 infants and 1 adult were referred to the University of California, San Diego, for surgical treatment of SVAS. A subset of 9 patients had both SVAS and LMCA and are the focus of this article.

Of the 9 patients with LMCA and SVAS, 6 patients were female and 3 were male. The mean age at operation was 5.5 years (range 0.2-32.4 years). Each patient underwent preoperative 2-dimensional echocardiography, color flow imaging, and cardiac catheterization before the operation. Five patients (group 1) had SVAS with a mean preoperative systolic gradient of $61.6 \mathrm{~mm} \mathrm{Hg}$ and near-circumferential ostial LMCA stenosis, causing more than $70 \%$ narrowing diagnosed by cardiac angiography (Fig 1). Of these, 4 patients had SVAS proximal to the innominate artery, and 1 patient had diffuse SVAS extending to the distal aortic arch. Four of these patients also had pulmonary valve stenosis with or without pulmonary artery disease. One child (patient 4) in this group had severe cardiomyopathy with aortic and mitral regurgitation.

Two patients (group 2) had SVAS (mean preoperative systolic gradient $42.5 \mathrm{~mm} \mathrm{Hg}$ ) diagnosed by cardiac catheterization and restricted coronary blood flow caused by partial fusion of the left aortic valve leaflet to an obstructing ridge of tissue immediately above the LMCA orifice (Fig 1). The mechanical etiology for LMCA obstruction in 1 patient in group 2 was ascertained at the time of the operation, not by preoperative studies. One child (patient 6) had the concomitant anomaly of supravalvular pulmonic stenosis. Both patients in this group had limited focal SVAS in the region of the sinotubular junction.

Two patients (group 3) had SVAS with a mean systolic gradient of $66.0 \mathrm{~mm} \mathrm{Hg}$ and LMCA fusiform narrowing extending into the left anterior descending artery on cardiac catheterization (Fig 1). The adult patient in group 3 (patient 9) also had a 


\section{Type I}

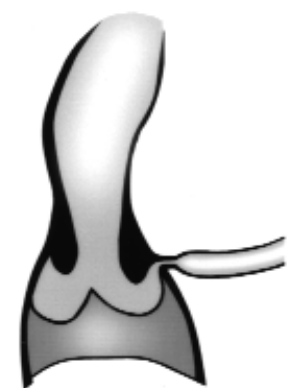

Ostial Narrowing
Type II

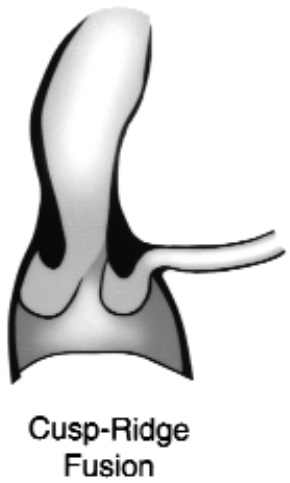

Type III

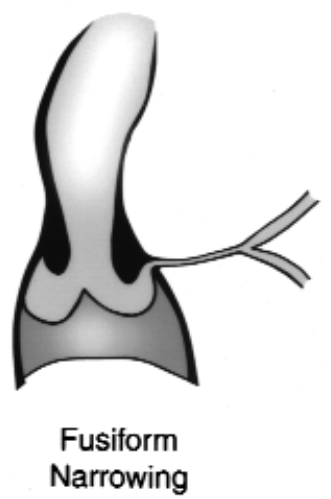

Fig 4. Classification of LMCA obstruction in SVAS.

dysplastic aortic valve with aortic insufficiency. Both group 3 patients had SVAS limited to the ascending aorta. Five of the 9 patients reviewed for this study had Williams syndrome.

Operative management. All patients underwent simultaneous relief of SVAS and LMCA stenosis with cardiopulmonary bypass, moderate hypothermia, and antegrade crystalloid cardioplegic arrest. Topical cooling was also used. In each patient, an oblique aortotomy was performed above the aortic sinuses on the anterior surface of the aorta to allow inspection of the sinuses of Valsalva and aortic valve. It was thereby possible to verify the expected morphologic characteristics and evaluate the effect of asymmetric sinus deformity on the aortic valve cusps.

In group 1 patients (LMCA ostial narrowing) the aortotomy was extended in a spiral fashion to the left and posteriorly into the LMCA ostium (Fig 2, A). Minimal dissection between the pulmonary artery and aorta afforded excellent exposure. This incision resulted in release of the SVAS and ostial LMCA narrowing. A spatulated pointed patch of bovine or native pericardium was subsequently used to close the defect. Running 7-0 polypropylene suture was used to approximate the patch to the LMCA and the aortic wall. The patch was tapered to close the aortic defect (Fig 2, B).

In group 2 patients, visual inspection through an anterior aortotomy revealed LMCA obstruction caused by partial fusion or tethering of the midpoint of the left aortic valve leaflet to the supra-aortic stenotic ridge superior to the LMCA ostium. This anatomy resulted in a loose hood of valve tissue obstructing the LMCA orifice. In each case, the valve leaflet was excised sharply from the aortic wall with a No. 11 blade, with preservation of all possible leaflet tissue (Fig 3). After relief of LMCA obstruction, the aortotomy was extended into the left coronary sinus, avoiding the left coronary ostium. Single patch aortoplasty with native pericardium and 5-0 running polypropylene was then used to close the defect. Valve competency was assessed by direct visualization of leaflet coaptation and mobility.

The 2 patients in group 3 (fusiform long-segment narrowing of the LMCA extending past the bifurcation) were treat- ed by coronary artery bypass grafting with saphenous vein grafts to the left anterior descending artery and circumflex coronary artery. The SVAS in these patients was corrected by an anterior oblique aortotomy extending into the noncoronary sinus with native pericardium used for patch closure.

Concomitant procedures were patch arterioplasty of the main, left, or right pulmonary arteries (4 patients), closure of a persistent foramen ovale (1 patient), ligation of a persistent ductus arteriosus (1 patient), and aortic valve replacement (1 patient).

Data. Patient clinical charts, operative and diagnostic reports of cardiac catheterization, and echocardiograms were reviewed retrospectively. Follow-up consisted in reviewing all last visits to attending pediatric or adult cardiologists that included Doppler echocardiographic assessment or postoperative heart catheterization. One patient (patient 9) was lost to follow-up after he moved to another country. Mean length of follow-up (excluding the 1 early death) was 54.8 months with a range of 6 to 97 months.

\section{Results}

Nine patients with SVAS and LMCA obstruction were referred for surgical repair (Table I). In 7 patients, the diagnosis of LMCA stenosis was made before the operation. In 1 patient with a fused left coronary leaflet, the coronary obstruction was diagnosed during the operation. Two patients came to the operating room on an emergency basis, 1 in arrest (patient 4) and 1 supported by percutaneous cardiopulmonary bypass (patient 9), instituted after ventricular fibrillation in the cardiac catheterization suite. Patients 3 and 8 had preoperative electrocardiograms suggestive of acute ischemia.

One early death occurred within 24 hours of the operation. This occurred in a 5-year-old girl who had cardiac arrest in the catheterization unit and was brought to the operating room in extremis while undergoing 
Table I. Clinical and operative characteristics

\begin{tabular}{|c|c|c|c|c|}
\hline & \multirow{2}{*}{$\begin{array}{c}\text { Patient } \\
\text { (age [y], sex) }\end{array}$} & \multicolumn{2}{|c|}{$\begin{array}{c}\text { Systolic } \\
\text { gradient }(\mathrm{mm} \mathrm{Hg})\end{array}$} & \multirow[b]{2}{*}{ Other diagnoses } \\
\hline & & Preop & Postop & \\
\hline \multicolumn{5}{|l|}{ Group 1} \\
\hline & $1(3.4, F)$ & 85 & 9 & Williams, PS, MPA stenosis \\
\hline & $2(0.2, F)$ & 65 & 5 & Williams, MPA and branch PA stenosis, PFO \\
\hline & $3(0.2, F)$ & 58 & 137 & Williams, MPA and branch PA stenosis, PDA \\
\hline & $4(5.2, \mathrm{~F})$ & 40 & ND & Williams, cardiomyopathy, MR, AI, dysplastic AV \\
\hline & $5(0.8, M)$ & 60 & 10 & MPA and LPA stenosis \\
\hline \multicolumn{5}{|l|}{ Group 2} \\
\hline & $6(2.1, \mathrm{M})$ & 50 & 2 & PS, MPA stenosis \\
\hline & $7(1.7, \mathrm{~F})$ & 35 & 7 & Williams \\
\hline \multicolumn{5}{|l|}{ Group 3} \\
\hline & $8(3.9, F)$ & 57 & 5 & None \\
\hline & $9(32.4, \mathrm{M})$ & 75 & 15 & Dysplastic AV, AI \\
\hline
\end{tabular}

$P S$, Pulmonary stenosis; $M P A$, main pulmonary artery; $L M C A$, left main coronary artery; $P A$, pulmonary artery; $P F O$, persistent foramen ovale; $L P A$, left pulmonary artery; $R P A$, right pulmonary artery; $P D A$, persistent ductus arteriosus; $N D$, not done; $M R$, mitral regurgitation; $A I$, aortic insufficiency; $A V$, aortic valve; $P O D$, postoperative day; $C A B G$, coronary artery bypass graft.

cardiac massage (patient 4). In addition to SVAS and ostial LMCA stenosis, this child had cardiomyopathy with severe mitral and aortic regurgitation.

All surviving patients underwent follow-up echocardiography with or without cardiac catheterization at a mean of 54.8 months (range 6-97 months). A significant reduction of the systolic supravalvular gradient to $10 \mathrm{~mm} \mathrm{Hg}$ or less was achieved in all but 1 patient. The child with the residual supravalvular aortic gradient (patient 3 ) was originally treated with patch augmentation limited to the ascending aorta and LMCA ostium. Early follow-up catheterization revealed a residual gradient at the level of the aortic arch, and she subsequently underwent extended patch aortoplasty of the arch and proximal descending aorta 6 months after the first operation.

Two patients required further interventions for recurrent pulmonary artery/pulmonary valve disease. Patient 2 required balloon dilatation for bilateral peripheral pulmonary artery stenosis 65 months after the operation, and patient 5 required a right ventricular-pulmonary artery homograft for infundibular and main pulmonary artery stenosis 21 months after the operation.

The mean ejection fraction at 1 postoperative month for the 8 surviving patients was $68 \%$ (range $50 \%-72 \%$ ) and at a mean follow-up of 54.8 months was $65 \%$ (range 45\%-70\%). Five patients who had left ventricular hypertrophy by electrocardiographic voltage criteria (patients 1,2, 6, 7, and 8) before the operation had subsequent normal electrocardiographic findings during the follow-up period. Long-term study of aortic valve function in all surviving patients by serial echocardio- grams revealed trace aortic valve incompetence in 2 infants (patients 5 and 7) at postoperative weeks 97 and 65 , respectively.

All surviving patients are currently free of angina. The 7 children who underwent surgical repair have normal growth parameters and exercise tolerance. The 1 adult patient returned to work as a laborer. There have been no late deaths.

\section{Discussion}

SVAS is a complex lesion that often involves the entire left ventricular outflow tract. The intimal hyperplasia and medial thickening seen in this disorder may be localized or diffuse within the aortic wall, resulting in hypoplastic aortic sinuses, commissural distortion, and ostial LMCA stenosis. ${ }^{8}$

Approximately $80 \%$ of the blood supply to the left ventricle is delivered through the LMCA. ${ }^{9}$ Critical narrowing of this vessel is one of the most lethal forms of heart disease and is uncommon in children. ${ }^{10}$ In this small series, we report a classification scheme for three anatomic forms of LMCA obstruction associated with SVAS (Fig 4). Type I LMCA stenosis is a direct result of near-circumferential narrowing from medial wall hypertrophy in the first few millimeters of the artery at its aortic origin. Type II LMCA obstruction results from fusion of the free edges of the left coronary cusp to the aortic wall, effectively isolating the sinus of Valsalva and coronary ostium from the lumen of the aorta. In type III disease, diffuse long-segment narrowing of the LMCA to the bifurcation is present.

Several types of repair for SVAS have been proposed to achieve anatomic geometry of the aortic root with 
Patch aortoplasty into LMCA, transvalvular PA patch

Patch aortoplasty into LMCA, closure PFO, enlarge MPA, LPA, RPA

Patch aortoplasty into LMCA, ligation PDA, enlarge MPA, LPA, RPA

Patch aortoplasty into LMCA

Patch aortoplasty into LMCA, enlarge MPA, LPA

Excision fused aortic leaflet, patch aortoplasty, transvalvular PA patch

Excision fused aortic leaflet, patch aortoplasty

Patch aortoplasty, $\mathrm{CABG} \times 2$

Patch aortoplasty, $\mathrm{CABG} \times 2, \mathrm{AVR}$

$\begin{array}{lc}\text { Native } & 26 \text { (alive) } \\ \text { Native } & 65 \text { (alive) } \\ \text { Bovine } & 10 \text { (alive) } \\ \text { Native } & \text { Dead POD 0 } \\ \text { Native } & 97 \text { (alive) } \\ & \\ \text { Native } & 73 \text { (alive) } \\ \text { Native } & 65 \text { (alive) } \\ & \\ \text { Bovine } & 96 \text { (alive) } \\ \text { Bovine } & 6 \text { (alive) }\end{array}$

favorable long-term results. These methods include enlargement with (1) a teardrop-shaped patch into a longitudinal incision that extends across the stenosis from the ascending aorta into the noncoronary sinus, first described by McGoon and colleagues ${ }^{11}$ in 1961; (2) an extended aortoplasty involving the insertion of a Y-shaped Dacron patch that branches into the right and noncoronary sinuses, described by Doty, ${ }^{12}$ Harlan, ${ }^{13}$ Steinberg, ${ }^{14}$ and their associates; (3) reconstruction of all three sinuses, advocated by Brom ${ }^{15}$ and Myers and coworkers $^{16}$; and (4) resection of the aortic stenotic segment with end-to-end reconstruction, reported by Chard and Cartmill. ${ }^{17}$ Despite differences in restoration of aortic root symmetry, to date no difference has been reported in long-term outcome for any of these surgical techniques, ${ }^{18}$ although Stamm and colleagues ${ }^{19}$ have reported a lower reoperative rate for patients undergoing multiple sinus reconstructions of the aortic root in SVAS.

We believe it is imperative both to restore the coronary blood flow and to reconstruct the aortic root in patients with SVAS whose cases are complicated by obstruction of the left coronary ostium. The surgical approach used for correction of these two entities depends on the anatomic configuration of LMCA narrowing. Patients with disease limited to the ostium of the LMCA may be treated by combined aortoplasty and ostioplasty. We found that excellent exposure obtained by the anterior approach allows a thorough inspection of the LMCA before incising into its ostium. There was no need in these patients to divide the pulmonary artery for exposure, as has been previously reported. ${ }^{20} \mathrm{LMCA}$ surgical ostioplasty with native or bovine pericardium restored physiologic perfusion of the left coronary tree, and extension of the patch into the stenotic aortic region relieved the SVAS component of the disease.

The technique of ostioplasty of the LMCA in adults is not a new concept, having been first reported in 1965 when Sabiston and coworkers ${ }^{21}$ enlarged an LMCA ostium with a pericardial autograft patch in a young woman with fibrocalcific plaque. In 1970 Najafi, Escamilla, and Clark $^{22}$ reported the first transaortic saphenous vein patch ostioplasty for an iatrogenic left main stenosis in a young woman after a valve operation. Subsequent series in adult patients reported by Hitchcock, ${ }^{23}$ Sullivan, ${ }^{24}$ Briffa, ${ }^{25}$ and their coworkers with saphenous vein patches and autologus pericardial patches confirm good long-term patency rates of the LMCA with long-term survival similar to that of patients undergoing coronary artery bypass for LMCA stenosis. In our series, we used native pericardium for patching the LMCA in 5 patients and bovine pericardium for patching the LMCA in only 1 patient. Given the small number of patients in this series, it was not possible to determine whether one type of LMCA patch material offered better patency than another patch material.

The anatomy of some patients does not favor the ostioplastic enlargement of the LMCA. Infants with SVAS and adherence of the left valve cusp to the aortic sinus wall (type II) were treated in this series with excision of the coronary leaflet and anterior aortoplasty. Aortic valve replacement, as has been reported for this condition, ${ }^{26}$ was not necessary. The LMCA ostia in these children were morphologically normal in appearance and size. Obstruction to left main flow was due to 
exclusion of the coronary ostium from the aortic lumen by the fused valve leaflet.

A small subset of our patients had diffuse LMCA narrowing extending at least to the bifurcation of the vessel. These 2 patients were treated with aortoplasty and coronary artery bypass grafting. In the series of left main surgical angioplasties reported by Dion and associates $^{27}$ in adults, diffuse disease involving the LMCA bifurcation was a well-defined contraindication for patch angioplasty. We chose vein conduits for these patients because of the concern of possible aortic arch disease in patients with SVAS.

In summary, this report describes the cases of 9 patients with SVAS in whom LMCA obstruction was present. Although our series is small, the early results of direct surgical intervention for proximal coronary obstruction are promising. It is important to identify patients having SVAS with LMCA obstruction, particularly when symptoms of angina or electrocardiographic changes of ischemia are present. The surgical approach to each patient should be determined by the anatomic type of LMCA stenosis/obstruction present.

\section{REFERENCES}

1. O'Connor WN, Davis JB Jr, Geissler R, Cottrill CM, Noonan JA, Todd EP. Supravalvular aortic stenosis. Arch Pathol Lab Med 1985;109:179-85.

2. Wren C, Oslizlok P, Bull C. Natural history of supravalvular aortic stenosis and pulmonary artery stenosis. J Am Coll Cardiol 1990;15:1625-30.

3. Keating MT. Genetic approaches to cardiovascular disease: supravalvular aortic stenosis, Williams syndrome, and long-QT syndrome. Circulation 1995;92:142-7.

4. Sun CC, Jacot J, Brenner JI. Sudden death in supravalvular aortic stenosis: fusion of a coronary leaflet to the sinus ridge, dysplasia and stenosis of aortic and pulmonic leaflets. Pediatr Pathol 1992;12:751-9.

5. Martin MM, Lemmer JH, Shaffer E, Dick M, Bove EL. Obstruction to left coronary artery blood flow secondary to obliteration of the coronary ostium in supravalvular aortic stenosis. Ann Thorac Surg 1988;45:16-20.

6. Flaker G, Teske D, Kilman J, Hosier D, Wooley C. Supravalvular aortic stenosis: a 20-year clinical perspective and experience with patch aortoplasty. Am J Cardiol 1983;51:256-60.

7. Allen HD, Moller JH, Formanek A, Nicoloff D. Atresia of the proximal left coronary artery associated with supravalvular aortic stenosis. J Thorac Cardiovasc Surg 1974;67:266-71.

8. McElhinney DB, Petrossian E, Tworetzky W, Silverman NH, Hanley FL. Issues and outcomes in the management of supravalvular aortic stenosis. Ann Thorac Surg 2000;69:562-7.

9. Loop FD, Lytle BW, Cosgrove DM, Sheldon WC, Irarrazaval M, Taylor PC, et al. Atherosclerosis of the left main coronary artery: 5 year results of surgical treatment. Am J Cardiol 1979;44:195-201.
10. Josa M, Danielson GK, Weidman WH, Edwards WD. Congenital ostial membrane of left main coronary artery. J Thorac Cardiovasc Surg 1981;81:338-46.

11. McGoon DC, Mankin HT, Vlad P, Kirklin JW. The surgical treatment of supravalvular aortic stenosis. J Thorac Cardiovasc Surg 1961;41:125-53.

12. Doty DB, Polansky DB, Jensen CB. Supravalular aortic stenosis: repair by extended aortoplasty. J Thorac Cardiovasc Surg 1977;74:362-71.

13. Harlan JL, Clark EB, Doty DB. Congenital aortic stenosis with hypoplasia of the left sinus of Valsalva: anatomic reconstruction of the aortic root. J Thorac Cardiovasc Surg 1985;89:288-94.

14. Steinberg JB, Delius RE, Behrendt DM. Supravalvular aortic stenosis: a modification of extended aortoplasty. Ann Thorac Surg 1998;65:277-9.

15. Brom AG. Obstruction of the left ventricular outflow tract. In: Khonsari S, editor. Cardiac surgery: safeguards and pitfalls in operative technique. Rockville (MD): Lippincott Williams \& Wilkins; 1988. p. 276-80.

16. Myers JL, Waldhausen JA, Cyran SE, Gleason MM, Weber HS, Baylen BG. Results of surgical repair of congenital aortic stenosis. J Thorac Cardiovasc Surg 1993;105:281-7.

17. Chard RB, Cartmill TB. Localized supravalvular aortic stenosis: a new technique for repair. Ann Thorac Surg 1993;55:782-4.

18. Hazekamp MG, Kappetein AP, Schoof PH, Ottenkamp J, Witsenburg M, Huysmans, HA, et al. Brom's three-patch technique for repair of supravalvular aortic stenosis. J Thorac Cardiovasc Surg 1999;118:252-8.

19. Stamm C, Kreutzer C, Zurakowski, Nollert G, Friehs I, Mayer JE, et al. Forty-one years of surgical experience with congenital supravalvular aortic stenosis. J Thorac Cardiovasc Surg 1999;118:874-85.

20. Dion R, Elias B, Khoury GEI, Moirhomme P, Verhelst R, Hanet C. Surgical angioplasty of the left main coronary artery. Eur J Cardiothorac Surg 1997;11:857-64.

21. Sabiston DC Jr, Ebert PA, Friesinger GC, Ross RS, SinclairSmith B. Proximal endarterectomy, arterial reconstruction for coronary occlusion at aortic origin. Arch Surg 1965;91:758-64.

22. Najafi H, Escamilla HA, Clark JG. Acute coronary insufficiency and life-threatening cardiac arrhythmias eight months after triple heart valve replacement. Surg Clin North Am 1970;50:1119-27.

23. Hitchcock JF, Robles de Medina EO, Janbroes G. Angioplasty of the left main coronary artery for isolated left main coronary artery disease. J Thorac Cardiovasc Surg 1983;85:880-4.

24. Sullivan JA, Murphy DA. Surgical repair of stenotic ostial lesions of the left main coronary artery. J Thorac Cardiovasc Surg 1989;98:33-6.

25. Briffa NP, Clarke S, Kugan G, Coulden R, Wallwork J, Nashef SA. Surgical angioplasty of the left main coronary artery: followup with magnetic resonance imaging. Ann Thorac Surg 1996;62:550-2.

26. Delius RE, Steinberg JB, L'Ecuyer T, Doty DB, Behrendt DM. Long-term follow-up of extended aortoplasty for supravalvular aortic stenosis. J Thorac Cardiovasc Surg 1995;109:155-63.

27. Dion R, Verhelst R, Matta A, Rousseau M, Goenen M, Chalant C. Surgical angioplasty of the left main coronary artery. J Thorac Cardiovasc Surg 1990;99:241-50. 